\title{
ANALISIS TINGKAT KEPUASAN MAHASISWA ATAS KUALITAS PELAYANAN LAYANAN ADMINISTRASI MAHASISWA UNIVERSITAS BUNDA MULIA, JAKARTA
}

\author{
William Darius dan Arko Pujadi \\ Email:wdarius@bundamulia.ac.id \\ Arkopujadi@yahoo.com
}

\section{Penulis}

William Darius adalah alumni Universitas Bunda Mulia dan merupakan staff Layanan Administrasi Mahasiswa Universitas Bunda Mulia

Arko Pujadi adalah staf pengajar tidak tetap di Jurusan Manajemen, Universitas Bunda Mulia, Jakarta dan menjadi koordinator dalam bidangMatematika Bisnis

\section{Abstract}

The purpose of this research is to find out about the difference between expectation of University of Bunda Mulia students and the performance of Layanan Administrasi Mahasiswa performances.

This research is descriptive research. The method of sampling is non probability sampling and the technique is purposive sampling. The sample consists of 100 respondent that obtained from Bunda Mulia University students in odd semester period 2009/2010. The result of this research shows that Bunda Mulia University students feel satisfy with Layanan Administrasi Mahasiswa service after compare Layanan Administrasi Mahasiswa performances with Bunda Mulia University student's expectation.

\section{Key Words}

Service quality, Satisfaction, Performances 


\section{PENDAHULUAN}

Kondisi perekonomian Indonesia yang semakin tidak menentu menyebabkan banyak permasalahan yang timbul dalam kehidupan bermasyarakat. Salah satunya yaitu tingginya tingkat pertumbuhan penduduk terutama di kota besar, yang mengakibatkan semakin tigginya populasi di suatu daerah. Seiring dengan semakin padatnya populasi penduduk yang tidak diikuti peningkatan penghasilan perkapita menjadikan masyarakat memiliki beban berat dalam memenuhi kebutuhannya. Dalam hal ini kebutuhan hidup manusia yaitu, meliputi pangan, sandang, dan papan serta kebutuhan akan pendidikan semakin meningkat pula terutama di negara berkembang. Salah satunya Indonesia, pemenuhan kebutuhan pendidikan baik formal maupun non - formal sangat dibutuhkan karena hal ini dapat memberikan dampak yang besar terhadap penduduk dalam rangka peningkatan kualitas SDM (Sumber Daya Manusia) Indonesia. Ada dua jenis pendidikan yang kita kenal di masyarakat kita, yaitu pendidikan formal (seperti TK, SD sampai Universitas), dan pendidikan nonformal (seperti kursus komputer, les Bahasa Inggris, maupun kegiatan beladiri).

Bunda Mulia merupakan salah satu lembaga pendidikan swasta di Jakarta. Lembaga tersebut menyediakan pendidikan dari jenjang TK, SD, SMP, SMA, SMK yang tergabung dalam Sekolah Bunda Mulia (SBM) yang mempunyai standar nasional dan Bunda Mulia International School (BMIS) yang mempunyai standar internasional. Lembaga ini juga menyediakan perguruan tinggi atau universitas yang diberi nama Universitas Bunda Mulia yang terletak di Jalan Lodan Raya No. 2, Jakarta Utara. Pada awalnya Universitas Bunda Mulia berasal dari STIE Bunda Mulia dan STMIK Bunda Mulia, dan seiring dengan perkembangan zaman, maka STIE Bunda Mulia dan STMIK Bunda Mulia digabung menjadi Universitas Bunda Mulia. 
Bidang usaha jasa pendidikan berupaya untuk meningkatkan kualitas pendidikan agar tidak kalah bersaing dengan perguruan tinggi lainnya. Dalam suatu sistem persaingan yang sempurna, dimana banyak perguruan tinggi menawarkan barang dan jasa yang sama, maka kunci untuk memenangkan persaingan adalah kualitas, khususnya kualitas pelayanan. Kualitas pelayanan sangat diperlukan agar tercipta kepuasan pelanggan.

\section{Perumusan Masalah}

Penelitian ini ingin mengetahui tingkat kepuasan mahasiswa Universitas Bunda Mulia berdasarkan kualitas pelayanan Layanan Administrasi Mahasiswa Universitas Bunda Mulia.

(Kotler 2007) jasa adalah setiap kegiatan atau kegiatan yang dapat ditawarkan oleh satu pihak kepada pihak lain, pada dasarnya tidak berwujud dan tida mengakibatkan kepemilikan apapun. Produksi jasa bisa berkaitan dengan produk fisik atau sebaliknya.

Pelanggan merasa puas apabila mereka memperoleh pelayanan yang baik atau sesuai dengan yang diharapkan. Dimensi kualitas yang diteliti oleh Zethaml, Parasuraman, dan Berry (Lovelock 2004). Dimensi tersebut dikenal dengan SERVQUAL, yang terdiri dari:

\section{Reliability}

Kemampuan perusahaan dalam memberikan jasa yang tepat dan dapat diandalkan. Hal ini juga berarti melaksanakan pelayanan yang dijanjikan secara akurat dan terpercaya.

\section{Responsiveness}

Untuk membantu dan memberikan pelayanan kepada pelanggan dengan cepat.

\section{Assurance}

Untuk mengukur kemampuan dan kesopanan karyawan serta sifat dapat dipercaya yang dimiliki oleh karyawan. 


\section{Empathy}

Bagaimana pemahaman karyawan terhadap kebutuhan konsumen serta perhatian yang diberikan oleh karyawan.

\section{Tangible}

Digunakan untuk mengukur penampilan fisik, peralatan, karyawan, serta sarana komunikasi.

(Supranto 2001) mendefinisikan kepuasan sebagai tingkat perasaan seseorang setelah membandingkan kinerja atau hasil yang dirasakannya dengan harapannya. Tingkat kepuasan merupakan fungsi dari perbedaan antara kinerja yang dirasakan dengan harapan. Apabila kinerja dibawah harapan, maka pelanggan akan sangat kecewa. Bila kinerja sesuai harapan, maka pelanggan akan sangat puas. Sedangkan bila kinerja melebihi harapan pelanggan akan sangat puas harapan pelanggan dapat dibentuk oleh pengalaman masa lampau, komentar dari kerabatnya serta janji dan informasi dari berbagai media. Pelanggan yang puas akan setia lebih lama, kurang sensitive terhadap harga dan memberi komentar yang baik tentang perusahaan tersebut.

\section{METODOLOGI PENELITIAN}

\section{Jenis Penelitian}

Jenis penelitian yang digunakan dalam penelitian ini adalah metode deskriptif. (Indriantoro dan Supomo 2002), penelitian deskriptif (descriptive research) merupakan penelitian terhadap masalah-masalah berupa fakta-fakta saat ini dari suatu populasi. Metode deskriptif dapat digunakan untuk mendeskripsikan tentang kepuasan pelanggan suatu perusahaan dengan mengukur tingkat kepuasaan yang menggunakan skala ordinal, seperti sangat puas, puas, cukup puas, kurang puas dan tidak puas.

\section{Jenis Data}


Pengumpulan data merupakan hal yang paling utama yang harus dilakukan oleh penulis untuk melakukan sebuah penelitian. Dalam rangka memperoleh data dan informasi yang diperlukan untuk menyusun penelitian ini, penulis menggunakan dua jenis data sebagai berikut :

a. Data Primer

Teknik pengumpulan data primer dilakukan dengan melakukan survei kepada responden melalui angket / kuesioner. Kuesioner merupakan satu set pertanyaan yang tersusun secara sistematis dan standard sehingga pertanyaan yang sama dapat diajukan kepada setiap responden. Sistematis yang dimaksudkan disini adalah bahwa item-item pertanyaan disusun menurut logika sesuai dengan maksud dan tujuan pengumpulan data. Sedangkan yang dimaksudkan dengan standard adalah setiap item pertanyaan mempunyai pengertian, konsep dan definisi yang sama (Supranto J, 2000,p23). Model kuesioner yang digunakan dalam penelitian ini berbentuk pilihan ganda untuk mengukur kualitas pelayanan dan kepuasan mahasiswa dengan format jawaban berdasarkan skala likert.

b. Data Sekunder

Teknik pengumpulan data sekunder dilakukan dengan menggunakan dokumendokumen yang dimiliki Layanan Administrasi Mahasiswa Universitas Bunda Mulia.

\section{Teknik Pengumpulan Data}

Dalam penyusunan penelitian ini penulis menghimpun data dan informasi dengan menggunakan cara-cara sebagai berikut :

a. Riset Kepustakaan (Library Research)

Yaitu pengumpulan data primer dan sekunder yang bersumber pada beberapa buku dan literatur yang berhubungan dengan penelitian atau dengan membaca di 
perpustakaan atau lembaga terkait yang mempunyai kaitan atau hubungan dengan penelitian yang dilakukan.

b. Penelitian Lapangan (Field Research)

1). Observasi

Pengumpulan data dilakukan dengan mengadakan pengamatan dan pencatatan secara langsung terhadap obyek penelitian, yaitu kepada mahasiswa Universitas Bunda Mulia.

2). Angket

Dengan cara meninjau atau mendatangi langsung objek penelitian, dengan menggunakan satu instrumen yaitu berupa angket yang disebarkan kepada mahasiswa Universitas Bunda Mulia.

\section{Populasi dan Sampel}

Populasi merupakan keseluruhan obyek penelitian sebagai sumber data yang memiliki karakteristik tertentu di dalam suatu penelitian. Sedangkan sampel merupakan himpunan bagian dari populasi yang menjadi obyek sesungguhnya.

Populasi dalam penelitian ini adalah mahasiswa Universitas Bunda Mulia. Jumlah mahasiswa aktif Universitas Bunda Mulia pada periode Ganjil 2009/2010 adalah sebanyak 2579 mahasiswa, untuk mendapatkan sample yang dapat menggambarkan dan mencadarkan populasi, maka dlam penelitian ini digunakan rumus Slovin (Umar 2004) sebagai berikut :

$$
\mathrm{n}=\frac{\mathrm{N}}{1+\mathrm{Ne}^{2}}
$$

Dimana :

$$
\begin{aligned}
& \mathrm{n}=\text { Ukuran sampel } \\
& \mathrm{N}=\text { Ukuran populasi }
\end{aligned}
$$


$\mathrm{e}=$ Persen kelonggaran ketidak telitian karena kesalahan pengambilan sampel yang masih dapat ditolerir.

Tabel 1

Jumlah Mahasiswa Aktif Semester Ganjil 2009/2010

\begin{tabular}{|l|c|c|c|c|c|c|c|c|c|}
\hline \multicolumn{1}{|c|}{ Jurusan } & $\begin{array}{c}200 \\
3\end{array}$ & $\begin{array}{l}200 \\
4\end{array}$ & 2005 & 2006 & 2007 & 2008 & 2009 & 2010 & Total \\
\hline Akuntansi & 0 & 7 & 45 & 58 & 98 & 69 & 122 & 0 & 399 \\
\hline Bahasa \& Budaya China & 0 & 0 & 2 & 16 & 8 & 12 & 33 & 0 & 71 \\
\hline $\begin{array}{l}\text { Bahasa \& Budaya } \\
\text { Inggris }\end{array}$ & 0 & 0 & 7 & 9 & 19 & 16 & 23 & 0 & 74 \\
\hline $\begin{array}{l}\text { Desain Komunikasi } \\
\text { Visual }\end{array}$ & 0 & 2 & 33 & 87 & 66 & 77 & 73 & 0 & 338 \\
\hline Ilmu Komunikasi & 0 & 5 & 19 & 84 & 57 & 77 & 117 & 0 & 359 \\
\hline Manajemen & 1 & 14 & 48 & 105 & 116 & 78 & 126 & 0 & 488 \\
\hline Perhotelan & 0 & 0 & 1 & 2 & 34 & 19 & 41 & 0 & 97 \\
\hline Psikologi & 0 & 4 & 10 & 13 & 18 & 22 & 19 & 0 & 86 \\
\hline Sistem Informasi & 1 & 4 & 38 & 98 & 90 & 91 & 125 & 0 & 447 \\
\hline Teknik Industri & 0 & 0 & 0 & 6 & 6 & 8 & 8 & 0 & 28 \\
\hline Teknik Informatika & 1 & 7 & 12 & 46 & 34 & 36 & 56 & 0 & 192 \\
\hline Total & 3 & 43 & 215 & 524 & 546 & 505 & 743 & 0 & 2579 \\
\hline
\end{tabular}

Sumber : Layanan Administrasi Mahasiswa Universitas Bunda Mulia, 2009

$$
\begin{aligned}
\mathrm{n} & =\frac{2579}{1+2579(10)^{2}} \\
& =100 \text { sampel }
\end{aligned}
$$




\section{Metode Pengambilan Sampel}

Metode pengambilan sampel yang digunakan pada penelitian ini adalah nonprobability sampling, dimana setiap unsure dalam populasi tidak memiliki kesempatan atau peluang yang sama untuk dipilih sebagai sample sedangkan teknik nonprobability sampling yang digunakan adalah purposive sampling. Penelitian ini menggunakan metode nonprobability sampling dengan teknik purposive sampling karena pelayanan LAM yang sama dan konsisten kepada setiap mahasiswa Universitas Bunda Mulia tanpa memandang jurusan dan angkatan dari seluruh mahasiswa Universitas Bunda Mulia.

\section{Skala Pengukuran Kuesioner}

Skala pengukuran yang digunakan di dalam kuesioner adalah skala Likert. Skala Likert yang digunakan adalah skala 5 tingkat. Dalam kuesioner penulisan menggunakan skala likert berikut ini pembobotan yang diberikan untuk setiap kategori jawaban :

Untuk variabel tingkat Harapan mahasiswa Universitas Bunda Mulia :

1. Jawaban sangat penting diberi bobot 5

2. Jawaban penting diberi bobot 4

3. Jawaban cukup penting diberi bobot 3

4. Jawaban kurang penting diberi bobot 2

5. Jawaban tidak penting diberi bobot 1

Sedangkan untuk kinerja (performance) yang ditunjukkan oleh Layanan

Administrasi Mahasiswa Universitas Bunda Mulia diberi pembobotan sebagai berikut :

1. Jawaban sangat baik diberi bobot 5

2. Jawaban baik diberi bobot 4

3. Jawaban cukup baik diberi bobot 3

4. Jawaban kurang baik diberi bobot 2 
5. Jawaban tidak baik diberi bobot 1

(J. Supranto 2006 "kinerja dikatakan baik dan harapan dikatakan penting bila hasil perhitungan rata-ratanya berada diantara 3,5 - 4,5."

Selanjutnya dapat dicari skor rata-rata tingkat pelaksanaan dan skor rata-rata tingkat kepentingan atau harapan dari setiap faktor yang mempengaruhi kepuasan pelanggan :

Rumus: $T k i=\frac{X i}{Y i} x 100 \%$

Tki : Tingkat kesesuaian responden

$X i \quad$ : Skor penilaian kinerja perusahaan

$Y i \quad$ : Skor penilaian kinerja kepentingan

Selanjutnya sumbu mendatar $\mathrm{x}$ akan diisi oleh skor tingkat pelaksanan kinerja sedangkan sumbu tegak y diisi oleh skor tingkat kepentingan :

Rumus : $\bar{x}=\frac{\sum X i}{n} \quad, \bar{x}=\frac{\sum Y i}{n}$

$\bar{x} \quad$ : Skor rata-rata tingkat kinerja

$\bar{y} \quad$ : Skor rata-rata tingkat kepuasan atau harapan

n : Jumlah sampel yang diambil

\section{Diagram Kartesius}

Dengan menggunakan Diagram kartisius dapat pula ditunjukkan atribut apa saja dari suatu produk barang atau jasa yang dianggap penting oleh konsumen tetapi kurang mendapatkan perhatian dari pemimpin, atau manajemen kinerjanya kurang baik, sehingga mengecewakan konsumen. Diagram ini terdiri dari suatu bangunan yang dibagi atas 4 
(empat) bagian yang dibatasi oleh 2 (dua) garis yang dipotong tegak lurus pada titik sebagai berikut :

$\mathrm{X}=$ skor rata-rata diseluruh faktor tingkat kinerja Layanan Administrasi Mahasiswa Universitas Bunda Mulia

Y= skor rata-rata diseluruh faktor kepuasan mahasiswa Universitas Bunda Mulia

Kedua titik tersebut ditentukan dengan rumus sebagai berikut :

$$
\overline{\bar{X}}=\frac{\sum_{i=1} \overline{X i}}{K} \quad, \quad \overline{\bar{X}}=\frac{\sum_{i=1} \overline{X i}}{K}
$$

$\mathrm{K}=$ Jumlah faktor atau atribut yang mempengaruhi kepuasan pelanggan

Dengan memasukan semua elemen-elemen atau atribut yang mempengaruhi kepuasan pelanggan kedalam diagram kartisius dapat menjelaskan peringkat jasa menurut kepuasan pelanggan dan kinerja perusahaan serta mengidentifikasi tindakan apa yang diperlukan dan cara sebagai berikut : 


\section{Gambar 1}

\section{DIAGRAM KARTESIUS}

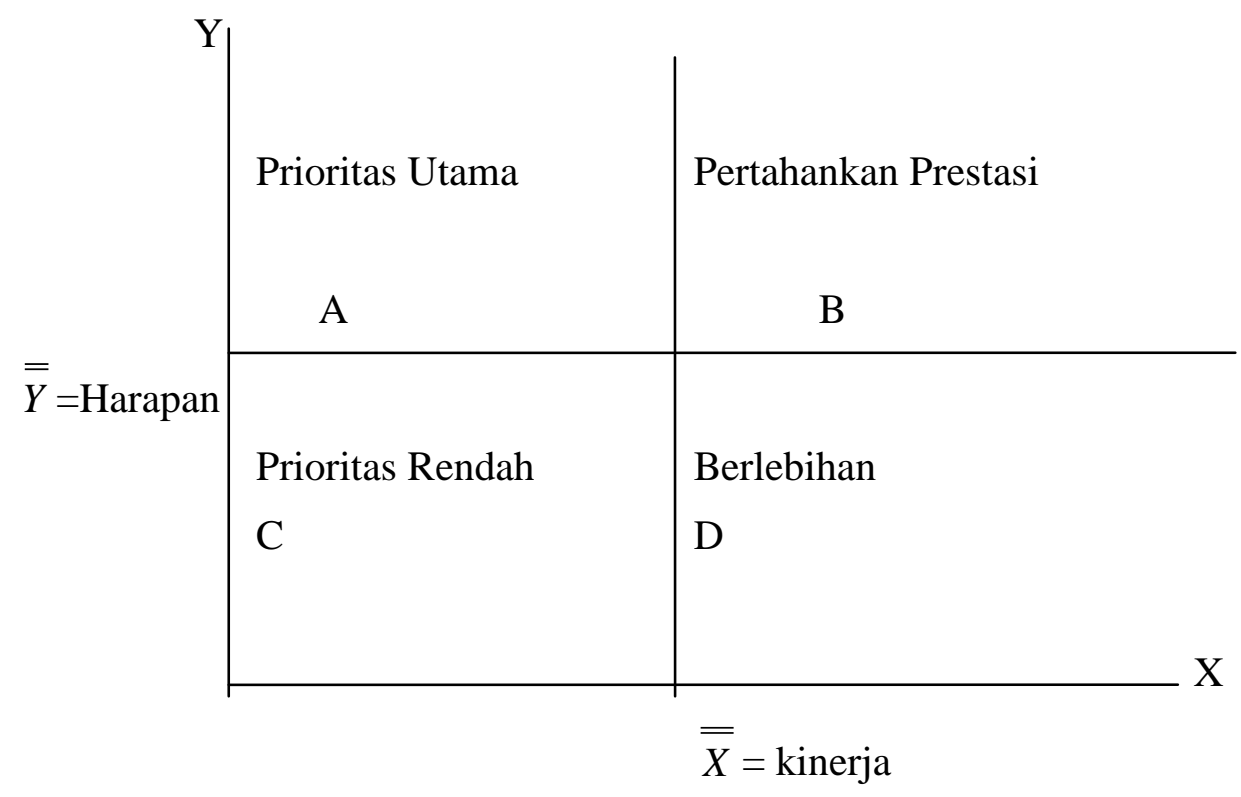

Sumber : diolah penulis

$\mathrm{A}=$ Elemen-elemen atau atribut-atribut jasa yang tingkat kepentingannya diatas ratarata tapi kurang mendapat perhatian Layanan Administrasi Mahasiswa Universitas Bunda Mulia sehingga kurang memuaskan bagi mahasiswa Universitas Bunda Mulia.

$\mathrm{B}=$ Menunjukkan elemen atau atribut yang dianggap penting oleh mahasiswa dan telah dilaksanakan dengan baik oleh pihak Layanan Administrasi Mahasiswa Universitas Bunda Mulia sehingga mahasiswa Universitas Bunda Mulia menjadi puas.

$\mathrm{C}=$ Kuadran ini menunjukkan elemen jasa yang dilaksanakan dengan secukupnya oleh pihak Layanan Administrasi Mahasiswa Universitas Bunda Mulia dan tidak dianggap sebagai suatu yang penting oleh mahasiswa Universitas Bunda Mulia.

$\mathrm{D}=$ Kuadran ini menunjukkan elemen jasa yang dianggap tidak begitu penting oleh mahasiswa Universitas Bunda Mulia namun dilaksanakan dengan sangat baik oleh 
Layanan Administrasi Mahasiswa Universitas Bunda Mulia yang mungkin terlihat berlebihan.

\section{ANALISIS DAN PEMBAHASAN}

\section{Uji Validitas dan Reliabilitas}

Uji validitas dan reliabilitas dilakukan untuk menguji kuesioner yang dibagikan kepada responden. Uji validitas menunjukkan sejauh mana suatu alat pengukur itu mampu mengukur apa yang diukur terhadap suatu benda. Sedangkan reliabilitas adalah istilah yang dipakai untuk menunjukkan sejauh mana suatu hasil pengukuran relatif konsisten, apabila pengukuran diulangi dua kali atau lebih.

Berdasarkan hasil pengolahan data dan analisis data menggunakan program SPPS versi 16, kuesioner yang disebarkan kepada mahasiswa Universitas Bunda Mulia dapat dilihat pada variabel kinerja pelayanan dan variabel harapan mahasiswa Universitas Bunda Mulia.

Sumber : diolah penulis

\section{Tabel 2}

\section{Uji Reliabilitas Variabel Kinerja Pelayanan}

\begin{tabular}{|r|r|}
\hline $\begin{array}{c}\text { Cronbach's } \\
\text { Alpha }\end{array}$ & N of Items \\
\hline .794 & 15 \\
\hline
\end{tabular}

Pada tabel Reliability Statistics memiliki nilai alpha cronbach sebesar 0,794 untuk variabel kinerja pelayanan. Hal ini dapat dikatakan sesuai dengan persyaratan skala pengukuran yang reliabel dengan nilai alpha cronbach minimal 0,70 maka setiap pertanyaan tersebut dinyatakan reliabel. 
Tabel 3

Uji Validitas Variabel Kinerja Pelayanan

\begin{tabular}{|c|c|c|}
\hline Indikator & Corrected Item-Total Correlation & Keterangan \\
\hline ITEM01 & .341 & Valid \\
\hline ITEM02 & .252 & Valid \\
\hline ITEM03 & .211 & Valid \\
\hline ITEM04 & .412 & Valid \\
\hline ITEM05 & .320 & Valid \\
\hline ITEM06 & .237 & Valid \\
\hline ITEM07 & .303 & Valid \\
\hline ITEM08 & .532 & Valid \\
\hline ITEM09 & .408 & Valid \\
\hline ITEM10 & .632 & Valid \\
\hline ITEM11 & .593 & Valid \\
\hline ITEM12 & .407 & Valid \\
\hline ITEM13 & .510 & Valid \\
\hline ITEM14 & .410 & Valid \\
\hline ITEM15 & & \\
\hline IT & & \\
\hline
\end{tabular}

Sumber : diolah penulis

Berdasarkan hasil analisis dengan SPSS 16.0 bahwa $\mathrm{r}$ hitung ( corrected itemtotal correlation ) setiap item yang diperoleh lebih besar dari $\mathrm{r}$ tabel ( $\mathrm{r}$ hitung > $\mathrm{r}$ tabel ), dimana $r$ tabel $=0,195$, yang diambil dari interval tingkat keyakinan 95\%. Sehingga dapat disimpulkan bahwa kuisioner tersebut valid. 
Tabel 4

\section{Uji Reliabilitas Variabel Harapan Mahasiswa}

\begin{tabular}{|r|r|}
\hline Cronbach's Alpha & N of Items \\
\hline .801 & 15 \\
\hline
\end{tabular}

Sumber : diolah penulis

Pada tabel Reliability Statistics memiliki nilai alpha cronbach sebesar 0,801 untuk variabel harapan mahasiswa. Hal ini dapat dikatakan sesuai dengan persyaratan skala pengukuran yang reliabel dengan nilai alpha cronbach minimal 0,70 maka setiap pertanyaan tersebut dinyatakan reliabel. 
Tabel 5

Uji Validitas Variabel Harapan Mahasiswa

\begin{tabular}{|l|c|c|}
\hline Indikator & Corrected Item-Total Correlation & Keterangan \\
\hline ITEM01 & .434 & Valid \\
\hline ITEM02 & .382 & Valid \\
\hline ITEM03 & .378 & Valid \\
\hline ITEM04 & .525 & Valid \\
\hline ITEM05 & .556 & Valid \\
\hline ITEM06 & .406 & Valid \\
\hline ITEM07 & .508 & Valid \\
\hline ITEM08 & .538 & Valid \\
\hline ITEM09 & .407 & Valid \\
\hline ITEM10 & .238 & Valid \\
\hline ITEM11 & .502 & Valid \\
\hline ITEM12 & .415 & Valid \\
\hline ITEM13 & .245 & Valid \\
\hline ITEM14 & .353 & Valid \\
\hline ITEM15 & & \\
\hline S46 : & & \\
\hline
\end{tabular}

Sumber : diolah penulis

Berdasarkan hasil analisis dengan SPSS 16.0 bahwa $\mathrm{r}$ hitung ( corrected itemtotal correlation ) setiap item yang diperoleh lebih besar dari $\mathrm{r}$ tabel ( $\mathrm{r}$ hitung $>\mathrm{r}$ tabel ), dimana $\mathrm{r}$ tabel $=0,195$, yang diambil dari interval kepercayaan 95\%. Sehingga dapat disimpulkan bahwa kuisioner tersebut valid. 


\section{Tabel 6}

Tingkat Kesesuai Kinerja - Harapan Layanan Mahasiswa

\begin{tabular}{|c|c|c|c|c|c|c|}
\hline NO & DAFTAR PERTANYAAN & $\begin{array}{r}\text { Skor } \\
\text { Kinerja }\end{array}$ & $\begin{array}{c}\text { Skor } \\
\text { Harapan }\end{array}$ & $\begin{array}{c}\bar{X} \\
\text { Kinerja }\end{array}$ & $\begin{array}{c}\bar{Y} \\
\text { Harapan }\end{array}$ & TKI \\
\hline 1 & Staf LAM menjawab pertanyaan dengan tepat & 316 & 434 & 3.16 & 4.34 & 72.81 \\
\hline 2 & $\begin{array}{l}\text { Kemampuan memberikan pelayanan sesuai dengan } \\
\text { janji staf LAM }\end{array}$ & 326 & 425 & 3.26 & 4.25 & 76.71 \\
\hline 3 & Prosedur pelayanan di LAM tidak berbelit-belit & 304 & 428 & 3.04 & 4.28 & 71.03 \\
\hline 4 & Staf LAM mempunyai kemauan untuk membantu saya & 289 & 430 & 2.89 & 4.3 & 67.21 \\
\hline 5 & Staf LAM menanggapi keluhan dengan segera & 305 & 425 & 3.05 & 4.25 & 71.76 \\
\hline 6 & Staf LAM memberikan informasi yang cepat dan jelas & 307 & 427 & 3.07 & 4.27 & 71.9 \\
\hline 7 & $\begin{array}{l}\text { Staf LAM secara konsisten ramah dan sopan dalam } \\
\text { memberikan pelayanan }\end{array}$ & 257 & 430 & 2.57 & 4.3 & 59.77 \\
\hline 8 & $\begin{array}{l}\text { Staf LAM mempunyai pengetahuan dan keterlampilan } \\
\text { yang baik untuk menjawab pertanyaan saya }\end{array}$ & 292 & 426 & 2.92 & 4.26 & 68.54 \\
\hline 9 & Staf LAM memberikan pelayanan secara menyeluruh dan tuntas & 258 & 424 & 2.58 & 4.24 & 60.85 \\
\hline 10 & Staf LAM memberikan perhatian secara khusus kepada saya & 302 & 419 & 3.02 & 4.19 & 72.08 \\
\hline 11 & Staf LAM merasa simpati atas masalah yang saya hadapi & 288 & 422 & 2.88 & 4.22 & 68.25 \\
\hline 12 & $\begin{array}{l}\text { Pelayanan staf LAM kepada semua mahasiswa tanpa } \\
\text { memandang status sosial dan lain-lain. }\end{array}$ & 292 & 417 & 2.92 & 4.17 & 70.02 \\
\hline 13 & Kebersihan dan kenyamanan di ruang LAM & 274 & 428 & 2.74 & 4.28 & 64.02 \\
\hline 14 & Penampilan staf LAM rapi dan bersih & 278 & 427 & 2.78 & 4.27 & 65.11 \\
\hline 15 & Tata letak LAM menarik secara visual & 282 & 422 & 2.82 & 4.22 & 66.82 \\
\hline & Rata-rata & - & - & 2.91 & 4.25 & 68.47 \\
\hline
\end{tabular}

(Sumber : Hasil Pengolahan Data) 
Gambar 2

Diagram Kartesius

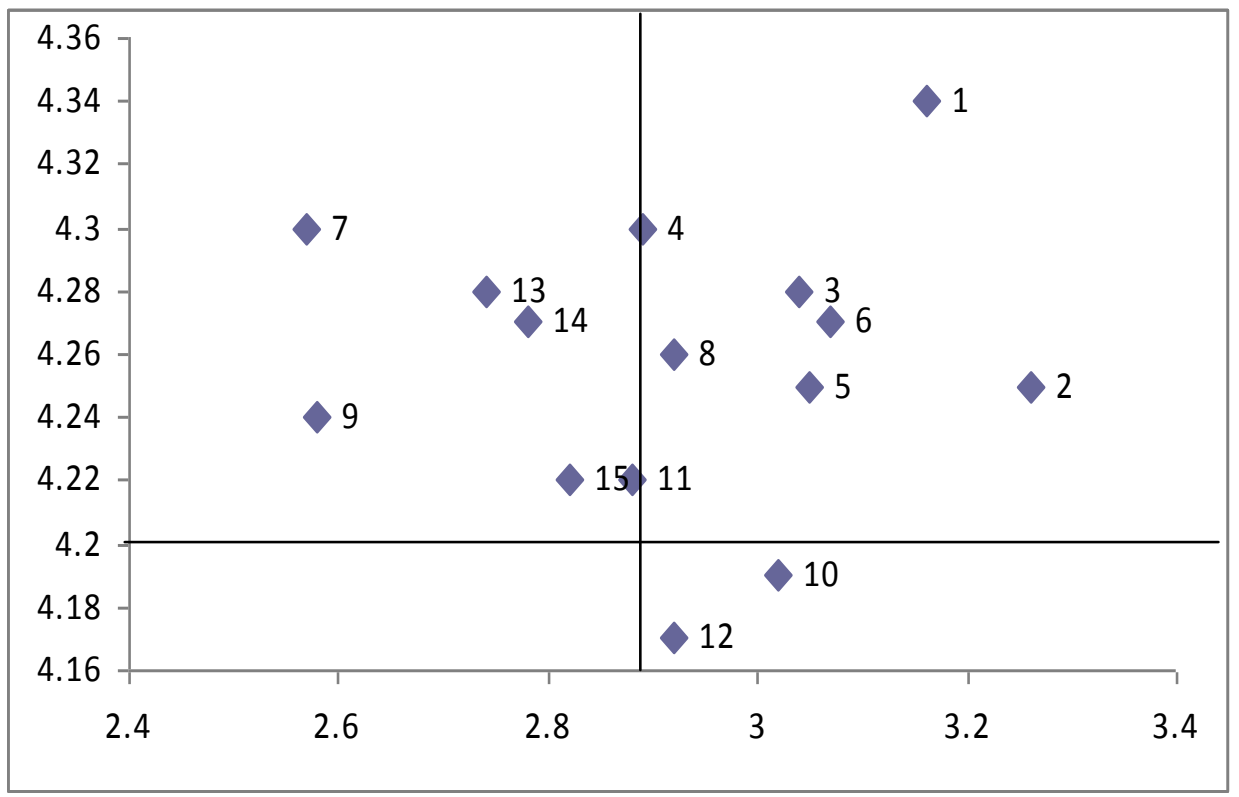

Sumber : diolah penulis

Keterangan :

1. Kuadran A

Menunjukkan elemen-elemen atau atribut yang mempengaruhi kepuasan mahasiswa Universitas Bunda Mulia berada dalam kuadran ini dan penanganannya diprioritaskan oleh perusahaan dan faktor ini dianggap penting bagi perusahaan, tapi kurang mendapat perhatian manajemen Universitas Bunda Mulia sehingga kurang memuaskan bagi mahasiswa.

Termasuk dalam kuadran A ini adalah :

a) Staf LAM mempunyai kemauan untuk membantu saya (4).

b) Staf LAM secara konsisten ramah dan sopan dalam memberikan pelayanan (7).

c) Kebersihan dan kenyamanan di ruang LAM (13).

d) Penampilan staf LAM rapi dan bersih (14). 
2. Kuadran B

Menunjukkan elemen atau atribut yang dianggap penting yang mempengaruhi kepuasan mahasiswa Universitas Bunda Mulia berada dalam kuadran ini perlu dipertahankan, karena pada umumnya tingkat pelaksanaannya telah sesuai dengan kepentingan dan harapan mahasiswa, dan telah dilaksanakan dengan baik oleh pihak manajemen Universitas Bunda Mulia sehingga mahasiswa menjadi puas.

Yang termasuk dalam kuadran B ini adalah :

a) Staf LAM menjawab pertanyaan dengan tepat (1).

b) Prosedur pelayanan di LAM tidak berbelit-belit (3).

c) Staf LAM menanggapi keluhan dengan segera (5).

d) Staf LAM memberikan informasi yang cepat dan jelas (6).

e) Staf LAM mempunyai pengetahuan dan keterlampilan yang baik untuk menjawab pertanyaan saya (8).

3 Kuadran C

Kuadran ini menunjukkan elemen jasa yang mempengaruhi kepuasan mahasiswa Universitas Bunda Mulia dianggap kurang penting, sedangkan pihak manajemen Universitas Bunda Mulia melaksanakannya dengan biasa saja atau cukup dan tidak dianggap sebagai suatu yang penting oleh mahasiswa.

Yang tarmasuk dalam kuadran $\mathrm{C}$ ini adalah :

a) Staf LAM memberikan pelayanan secara menyeluruh dan tuntas (9).

b) Staf LAM merasa simpati atas masalah yang saya hadapi (11).

c) Tata letak LAM menarik secara visual (15).

\section{Kuadran D}

Kuadaran ini menunjukkan elemen jasa yang dianggap tidak begitu penting oleh mahasiswa namun dilaksanakan dengan sangat baik oleh manajemen Universitas Bunda 
Mulia yang mungkin terlihat berlebihan. Akan tetapi pelaksanaanya baik sekali sehingga sangat memuaskan.

Yang termasuk dalah kuadran D ini adalah :

a) Kemampuan memberikan pelayanan sesuai dengan janji staf LAM (2).

b) Staf LAM memberikan perhatian secara khusus kepada saya (10).

c) Pelayanan staf LAM kepada semua mahasiswa tanpa memandang status sosial dan lain-lain (12).

\section{KESIMPULAN DAN SARAN}

\section{Kesimpulan}

Pada analisis tingkat kepuasan mahasiswa Universitas Bunda Mulia menunjukan bahwa mahasiswa merasa cukup puas dengan pelayanan yang diberikan Layanan Administrasi Mahasiswa Universitas Bunda Mulia. Hal ini terbukti dengan hasil rata-rata tingkat kesesuaian dari seluruh indikator sebesar $68.47 \%$.

\section{Saran}

Saran dari analisis kepuasan mahasiswa Universitas Bunda Mulia dengan menggunakan diagram kartesius adalah :

Kuadran A

Menunjukkan elemen-elemen atau atribut yang mempengaruhi kepuasan mahasiswa Universitas Bunda Mulia berada dalam kuadran ini dan penanganannya diprioritaskan oleh perusahaan dan faktor ini dianggap penting bagi perusahaan, tapi kurang mendapat perhatian manajemen Universitas Bunda Mulia sehingga kurang memuaskan bagi mahasiswa.

Yang termasuk dalam kuadran A ini adalah :

a) Staf LAM mempunyai kemauan untuk membantu saya (4).

b) Staf LAM secara konsisten ramah dan sopan dalam memberikan pelayanan (7).

c) Kebersihan dan kenyamanan di ruang LAM (13). 
d) Penampilan staf LAM rapi dan bersih (14).

Saran untuk indikator kuadran A adalah Universitas Bunda Mulia memberikan pelatihan dan motivasi kepada staf LAM agar memprioritaskan kemauan untuk membantu mahasiswa dalam setiap pelayanan yang diberikan, secara konsisten ramah dan sopan dalam memberikan pelayanan kepada mahasiswa dengan cara selalu tersenyum dan memberikan salam kepada setiap mahasiswa yang datang ke LAM, menjaga kebersihan dan ketenangan di ruang LAM agar mahasiswa merasa lebih nyaman berada di LAM, dan staf LAM memakai seragam agar terlihat lebih rapi dan bersih.

\section{Kuadran B}

Menunjukkan elemen atau atribut yang dianggap penting yang mempengaruhi kepuasan mahasiswa Universitas Bunda Mulia berada dalam kuadran ini perlu dipertahankan, karena pada umumnya tingkat pelaksanaannya telah sesuai dengan kepentingan dan harapan mahasiswa, dan telah dilaksanakan dengan baik oleh pihak manajemen Universitas Bunda Mulia sehingga mahasiswa menjadi puas.

Yang termasuk dalam kuadran B ini adalah :

a) Staf LAM menjawab pertanyaan dengan tepat (1).

b) Prosedur pelayanan di LAM tidak berbelit-belit (3).

c) Staf LAM menanggapi keluhan dengan segera (5).

d) Staf LAM memberikan informasi yang cepat dan jelas (6).

e) Staf LAM mempunyai pengetahuan dan keterlampilan yang baik untuk menjawab pertanyaan saya (8).

Saran untuk indikator kuadran B adalah mempertahankan dan meningkatkan kualitas pelayanan yang diberikan kepada mahasiswa Universitas Bunda Mulia sehingga mahasiswa Universitas Bunda Mulia merasa puas atas pelayanan yang diberikan. 
Kuadran C

Kuadran ini menunjukkan elemen jasa yang mempengaruhi kepuasan mahasiswa Universitas Bunda Mulia dianggap kurang penting, sedangkan pihak manajemen Universitas Bunda Mulia melaksanakannya dengan biasa saja atau cukup dan tidak dianggap sebagai suatu yang penting oleh mahasiswa.

Yang tarmasuk dalam kuadran $\mathrm{C}$ ini adalah :

a) Staf LAM memberikan pelayanan secara menyeluruh dan tuntas (9).

b) Staf LAM merasa simpati atas masalah yang saya hadapi (11).

c) Tata letak LAM menarik secara visual (15).

Saran untuk setiap indicator kuadran C adalah staf LAM tetap memberikan pelayanan secara menyeluruh dan tuntas karena pelayanan yang diberikan cukup penting oleh mahasiswa dalam kegiatan perkuliahan dengan cara tanggung jawab setiap staf LAM harus ditingkatkan dalam memberikan pelayanan secara menyeluruh dan tuntas, staf LAM tetap memperhatikan dan merasa simpati atas setiap masalah yang dihadapi oleh mahasiswa dengan cara membantu setiap mahasiswa pada saat berkonsultasi dan memberikan solusi atas masalah yang dihadapi, dan mendesain ulang tata letak LAM yang menarik secara visual agar mahasiswa merasa nyaman dengan tata letak yang baru.

\section{Kuadran D}

Kuadaran ini menunjukkan elemen jasa yang dianggap tidak begitu penting oleh mahasiswa namun dilaksanakan dengan sangat baik oleh manajemen Universitas Bunda Mulia yang mungkin terlihat berlebihan. Akan tetapi pelaksanaanya baik sekali sehingga sangat memuaskan.

Yang termasuk dalah kuadran D ini adalah : 
a) Kemampuan memberikan pelayanan sesuai dengan janji staf LAM (2).

b) Staf LAM memberikan perhatian secara khusus kepada saya (10).

c) Pelayanan staf LAM kepada semua mahasiswa tanpa memandang status sosial dan lain-lain (12).

Saran untuk kuadran D agar mempertahankan dan mengurangi atribut-atribut yang dianggap mahasiswa Universitas Bunda Mulia berlebihan.

\section{DAFTAR PUSTAKA}

Indriantoro, Nur dan Bambang, Supomo. 2002. Metodologi Penelitian Bisnis. BPFE, Yogyakarta.

Kotler, Philip. 2007. Manajemen Pemasaran. Edisi kedua belas. Jilid 4. Prenhalido. Jakarta

Lamb, Hair, McDaniel. 2005. Essentials of Marketing, $4^{\text {th }}$ ed.. Thomson South-Western, Mason, Ohio. United States of America.

Lovelock, Christopher, Wirtz, Jochen. 2004. Services Marketing in Asia. $5^{\text {th }}$ ed.. Prentice Hall, Pearson Education. Singapore.

Supranto, J. 2001. Pengukuran Tingkat Kepuasan Pelanggan untuk Menaikan Pangsa Pasar. Cetakan ke-2. Jakata.

Supranto, J. 2003. Metode Riset Aplikasinya Dalam Pemasaran. Edisi Kedua. PT Rineka Cipta. Jakarta.

Supranto, J. 2006. Pengukuran Tingkat Kepuasan Pelanggan. Edisi Ketiga. PT Rineka Cipta. Jakarta.

Uyanto, Stanislaus S, Ph. D. 2008. Pedoman Analisis Data dengan SPSS. Edisi 3, Graha Ilmu. Jakarta. 